\title{
Merged expertise, mutual benefits Using a cross-disciplinary, same-campus research team to investigate academic libraries
}

A cademic librarians have provided support to research teams on their campuses for many years. The main types of support discussed in the library literature include literature searching, citation management, data management, and information literacy instruction. Supporting research teams has been recommended as outreach, liaison work, and as part of the embedded librarians movement. Martin Kesselman and Sarah Watstein, for example, state, "In academic settings, embedded librarians are in collaborative learning environments. They are on research teams." Librarians' contributions to these teams will usually relate to what librarians are well trained to do: "captur[e] group knowledge" and "acquir[e] and organiz[e] internal and external information."1

Much has been written about health sciences librarians serving on research teams that are investigating nursing and health topics. These librarians mainly provide literature search services, but they can sometimes serve on systematic review teams. Robert Janke and Kathy Rush provide an example of this substantial literature. They write about a three-phase grant-funded project in British Columbia, Canada, that studied best practices to integrate new nurses into acute care settings. The librarian co-investigator did extensive literature review searching, corresponded with editors, addressed copyright issues, and helped write and revise publications and reports. ${ }^{2}$

Less common are accounts of librarians serving on research teams that are investi- gating topics related to academic libraries. Lesley Proctor, Richard Wartho, and Megan Anderson write about a research team at the University of Otago (New Zealand) that received a grant to embed information literacy into a first-year and third-year Sociology course and to assess the outcomes. The research team included Sociology instructors and an information literacy librarian. ${ }^{3}$

Since there are few accounts of research teams investigating academic library topics, I would like to share my experiences. In what follows, I describe the work of a research team at Appalachian State University, demonstrating how academic librarians, research faculty, and students can collaborate in mutually beneficial ways. ${ }^{4}$

\section{The project}

In early 2012, I decided to conduct a survey of performance appraisal systems for professional librarians in academic libraries.

I am a reference and instruction librarian with many years of involvement in the performance appraisal process by virtue of my position in a faculty-status academic library. I have written peer feedback statements as part of the annual performance appraisal process, and I have served on library personnel committees, promotion and tenure committees,

Glenn Ellen Starr Stilling is information literacy librarian and professor at Appalachian State University, email: stillngges@appstate.edu

(C) 2017 Glenn Ellen Starr Stilling 
search committees, and post-tenure review committees.

To place this practical experience in a broader perspective, I wanted to learn about how other academic libraries were handling performance appraisal, how much input librarians had into changing their system, how much feedback the librarians being evaluated were able to give and receive, and how effective the performance appraisal systems were viewed to be. My expertise gaps for this project were that I have neither administrative and human resources experience nor empirical research experience. Like many other academic librarians, I was not required to take a research methods course during my LIS program. ${ }^{5}$

I contacted Shawn Bergman, a professor in Appalachian's psychology department. His areas of expertise are industrial/ organizational psychology, research methodology, survey design, and quantitative methods. He

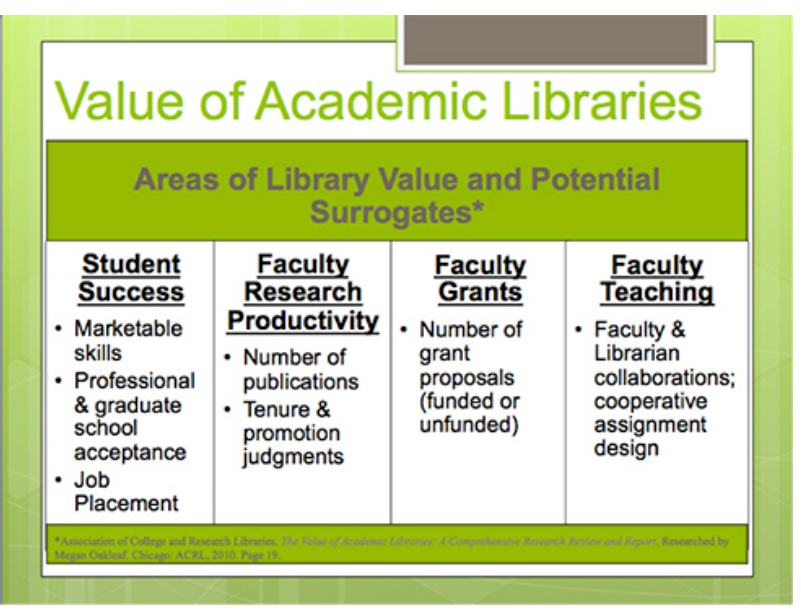

Areas where the research team's work aligns with ACRL's Value of Academic Libraries. teaches both

nar on enhancing student learning through group work, Barbara Jacoby-who specializes in service learning, civic engagement, and academic partnerships-recommends this approach. She states that teachers should "ensure that the group project is authentic, relevant, and sufficiently complex." The best way to do so, she says, is to relate the project to real-world issues. ${ }^{6}$

Bergman and I served as coprincipal investigators on the survey. He provided a graduate student and two undergraduate students for the project, with the graduate student organizing and supervising the work of the undergraduates. He and the students interacted with me as consultants, meeting with me once a week. By combining resources, we were able to develop a sampling frame of all libraries at four-year degree or higher institutions in the United States.

After the survey was deployed, I met regularly with the students, while Bergman undergraduate psychology students and graduate students in Appalachian's masters program in Industrial-Organizational Psychology and Human Resource Management, and he organizes students into teams to conduct research.

When I discussed my survey idea with him, he indicated that the project was well suited for him and his students, both because of the topic and because he has found that students prefer real-life projects to hypothetical case studies.

Bergman's preference to engage his students in real-life projects is supported by higher education literature. In an online semi- continued to mentor them outside of my meetings.

Through their interactions with us, students learned a variety of skills. Bergman worked with them on building a large contact database for the survey; designing survey questions; programming the survey, using survey software; submitting paperwork for IRB approval; handling survey data management and data analysis; and writing portions of a scholarly journal article reporting our findings. The graduate students also learned how to supervise and how to work using a consulting model. I worked with them on 
the organizational structure, professional work, and performance appraisal models of academic libraries; the author guidelines and article structure of the target LIS journal for our manuscript; and on literature searching.

\section{Mutual benefits, added value}

The resources Bergman and his students provided made the survey project much larger in scope, and better grounded in the relevant literature and practices outside of librarianship, than would otherwise have been possible. Collaboration also added value beyond the research results.

For instance, I learned much about conducting empirical research, analyzing the data, and writing a scholarly manuscript using quantitative data. Being integrally involved in the project made the learning experience vivid and meaningful. The benefits of real-world learning that Jacoby describes ${ }^{7}$ applied to me as well as to the students. I also learned by experience that substantial commitments of time, focus, and effort are required to see an empirical research project through to completion.

Second, our project allowed the library to add value to our institution in several ways that have been identified in ACRL's Value of Academic Libraries (VAL) report. ${ }^{8}$ In the VAL area of Student Success, the graduate students learned the marketable skills of supervision and working in a consultation model. Both undergraduate and graduate students learned presentation skills. They presented posters at a regional IndustrialOrganizational Psychology conference and placed in our graduate school's 3MT, or Three Minute Talk, competition.

One of the undergraduate students applied for, and was accepted to, our MBA program. I wrote a letter of reference that included information about his work on our project. Both of the graduate students who worked on our project are now employed in human resources management with large corporations. In the VAL area of Faculty Research Productivity, Bergman and I have coauthored one journal manuscript and are doing additional data analysis for another. Bergman was granted tenure after our survey was deployed, with this project being one he mentioned in his portfolio, and I successfully passed post-tenure review.

In the VAL area of Faculty Grants, we submitted an unfunded proposal for a campus-wide graduate student research mentor grant as well as a funded proposal for a library internal grant. In the VAL area of Faculty Teaching, our project represents both faculty/librarian collaboration and cooperative assignment design. Bergman and I cannot claim a causal relationship for any of these outcomes. I can, however, point them out as concrete ways in which the library has gone beyond customary service provision to contribute to our institution.

Finally, and most meaningful for me, was the opportunity to have deeper, more frequent interactions with students and nonlibrary faculty. Because I do not teach credit courses, and I supervise only one student assistant, I seldom have regular, extensive contact with students that extends beyond the current semester. Although I collaborate with nonlibrary faculty through library instruction and committee service, working together on a research team allowed fuller interaction than those roles. Each contact with team members brightened my day and added interest to my work life.

\section{Suggestions for working on librarian/ faculty/student teams}

Having worked with Bergman and his students since 2012, I see differences between a librarian's work life and theirs. I suggest that librarians who undertake this kind of collaboration keep the following in mind.

- Adjust your interaction and meeting style to your collaborators'. They might prefer a less formal style than librarians normally use in team and committee work.

- Be mindful of the deadlines and other commitments of your collaborators, both students and faculty, and stay attuned to the "seasons of the semester." Replace 
meetings with email progress reports during busy times.

- Discuss how the team will share authorship, allocate research and writing responsibilities, and alert each other to problems meeting deadlines (as should be done in any professional collaboration).?

- Be judicious in making requests that create additional work for your collaborators. Remember that the faculty member is also teaching and training the students so that they can provide what you need.

- Celebrate progress regularly, whether in emails, during team meetings, at significant stages of the project, or at the end of the semester. Teresa Amabile and Steven Kramer's research on the daily inner work life of hundreds of employees has shown that the "best way to motivate people, day in and day out, is by facilitating progress - even small wins." ${ }^{10}$

\section{Extending the concept}

Using cross-disciplinary research teams to study academic libraries is a concept that can be extended to other libraries. Two approaches can be used to generate research topics. First, librarians could identify library-related topics that could be investigated by partnering with faculty and students in their liaison areas.

Second, librarians might think about degree programs on their campus, and how these areas relate to libraries. For example, a campus with a sustainable development or alternative technologies program might study sustainability practices in library buildings.

\section{Conclusion: Rich rewards}

In the library literature, some writers have speculated about whether librarians would be accepted by nonlibrarians as members of a research team. On this project, however, I never doubted that our team valued what I brought to our collaboration. Any questions I asked about areas of our research that were outside my expertise were answered fully and respectfully. The posi- tive, progress-oriented spirit of our collaboration has made it one of the most engaging and gratifying experiences of my career.

\section{Notes}

1. Martin A. Kesselman and Sarah Barbara Watstein, "Creating Opportunities: Embedded Librarians," Journal of Library Administration 49, no. 4 (2009): 387.

2. Robert Janke and Kathy L. Rush, "The Academic Librarian as Co-Investigator on an Interprofessional Primary Research Team: A Case Study," Health Information \& Libraries Journal 31 (2014): 116-22.

3. Lesley Proctor, Richard Wartho, and Megan Anderson, "Embedding Information Literacy in the Sociology Program at the University of Otago," Australian Academic E Research Libraries 36, no. 4 (2005): 153-68.

4. A version of this article was presented as: Glenn Ellen Stilling, "Investigating Academic Libraries via a Cross-Disciplinary Survey Research Team: Multiple Data Sources, Multiple Impacts," 2nd Annual Empirical Librarians Conference, Bluford Library, North Carolina Agricultural and Technical State University, February 29, 2016.

5. Marie R. Kennedy and Kristine R. Brancolini, "Academic Librarian Research: A Survey of Attitudes, Involvement, and Perceived Capabilities," CERL 73, no. 5 (2012): 432.

6. Barbara Jacoby, "Seven Strategies to Enhance Learning through Group Work," Magna Online Seminars, Madison, WI: Magna Publications, March 5, 2014, Strategy 4.

7. Jacoby, Strategy 4.

8. Megan Oakleaf, The Value of Academic Libraries: A Comprehensive Research Review and Report (Chicago: Association of College and Research Libraries, 2010): 19.

9. Susan Robison, The Peak Performing Professor: A Practical Guide to Productivity and Happiness (San Francisco: Jossey-Bass, 2013): 157-62.

10. Teresa Amabile and Steven Kramer, The Progress Principle: Using Small Wins to Ignite Joy, Engagement, and Creativity at Work (Boston: Harvard Business Review P, 2011): 3. 2 